\title{
An EMF cell with a nitrogen solid electrolyte - on the transference of nitrogen ions in yttria-stabilized zirconia
}

\author{
Doh-Kwon Lee, $\dagger^{a}$ Claus C. Fischer, ${ }^{a}$ Ilia Valov, $\ddagger^{a}$ Jochen Reinacher, ${ }^{a}$ \\ Alexandra Stork, ${ }^{b}$ Martin Lerch ${ }^{b}$ and Juergen Janek*a
}

Received 9th March 2010, Accepted 14th October 2010

DOI: $10.1039 / \mathrm{c003991h}$

The mobility and electrochemical activity of nitrogen inside and/or at the surface of ionic compounds is of fundamental, as well as of possibly practical, relevance. In order to better understand the role of nitrogen anions in solid electrolytes, we measured the transference number of nitrogen in yttria-stabilized zirconia (YSZ) by a concentration cell technique as a function of oxygen activity at different temperatures in the range of $1023 \leq T / K \leq 1123$. YSZ doped with $1.9 \mathrm{wt} \%$ of $\mathrm{N}$ (YSZ:N) turned out to have an appreciable nitrogen transference number, which increased from 0 to 0.1 with decreasing oxygen activity in the range of $-20<\log a_{\mathrm{O}_{2}}<-14$. The stability of $\mathrm{N}$ in YSZ:N, however, has yet to be elucidated under oxidizing conditions.

\section{Introduction}

Nitrogen is usually regarded as (electro)chemically inert at most gas/solid interfaces or electrodes. This is partly because there has been no nitrogen solid electrolyte available so far. Only recently was nitrogen doping into cubic stabilized zirconia attempted as a possible alternative to cation doping, in light of the increase in oxygen vacancy concentration as well as phase stabilization. ${ }^{1-11}$ Whether the resulting crystalline and homogeneous quaternary fluorite-type oxide nitride phases can indeed be used as nitrogen electrolytes remains an open question to date.

Yttria-stabilized zirconia (YSZ) is one of the most intensively studied oxide ion conductors with an oxygen transference number $t_{\mathrm{O}^{2-}}$ ( $\equiv \sigma_{\mathrm{O}^{2-}} / \sigma_{\mathrm{tot}}$, where $\sigma_{\mathrm{O}^{2-}}$ and $\sigma_{\text {tot }}$ stand for the partial conductivity of oxygen ions and the total conductivity, respectively) close to unity. Hence, it is used as a solid electrolyte in a variety of applications, such as solid oxide fuel cells (SOFC), oxygen sensors, pumps or membranes, to name a few. The electrolytic functionality is facilitated by a large number of mobile oxygen vacancies formed to maintain the charge-neutrality with $\mathrm{Y}^{3+}$ ions in the $\mathrm{Zr}^{4+}$ sublattice. The concentration of oxygen vacancies can be additionally increased by heterogeneous nitrogen incorporation, which essentially leads to the substitution of oxygen, as represented in Kroeger-Vink notation ${ }^{1,5}$

$$
\mathrm{N}_{2}(\mathrm{~g})+3 \mathrm{O}_{\mathrm{O}}^{\times}=2 \mathrm{~N}_{\mathrm{O}}^{\prime}+\mathrm{V}_{\mathrm{O}}^{\bullet \bullet}+\frac{3}{2} \mathrm{O}_{2}(\mathrm{~g}),
$$

with $\mathrm{N}_{\mathrm{O}}^{\prime}$ denoting the $\mathrm{N}^{3-}$ ion on an $\mathrm{O}^{2-}$ site, $\mathrm{V}_{\mathrm{O}}^{\bullet \bullet}$ denoting the oxygen vacancy and $\mathrm{O}_{\mathrm{O}}^{\times}$representing the $\mathrm{O}^{2-}$ ion on a

\footnotetext{
${ }^{a}$ Institute of Physical Chemistry, Justus-Liebig-University,

Heinrich-Buff-Ring 58, D-35392 Giessen, Germany.

E-mail:Juergen.Janek@phys.Chemie.uni-giessen.de;

Fax: + 49-641-99-34509; Tel: + 49-641-99-34500

${ }^{b}$ TU Berlin, Institut für Chemie, Straße des 17. Juni 135,

D-10623 Berlin, Germany

$\dagger$ Current address: Solar Cell Center, Korea Institute of Science and

Technology (KIST), Seoul, 136-791, Korea; E-mail: dklee@kist.re.kr.

$\ddagger$ Current address: Institute for Solid State Research Electronic

Materials (IEM), Research Centre Juelich, D-52425 Juelich, Germany
}

regular anion site. Accordingly, N-doped YSZ has been found to have a higher ionic conductivity than "undoped", i.e. nitrogen-free, YSZ at high temperatures above $1000{ }^{\circ} \mathrm{C} .{ }^{5} \mathrm{At}$ lower temperatures, the ionic conductivity is poorer, probably due to strong interactions between nitrogen ions and vacancies. Up to now, the transport properties of YSZ:N were only reported in terms of total conductivity. Little is known about the mobility of nitrogen itself. ${ }^{6,12,13}$ In this paper, we report on the non-zero mobility of nitrogen in N-doped YSZ, determined by an open cell voltage measurement as a function of oxygen activity and temperature. The results also support our earlier observation that dinitrogen is electrochemically active at metal $\left(\mathrm{N}_{2}\right) /$ solid electrolyte electrodes. ${ }^{14,15}$

\section{Principles}

The open cell voltage measurement based on a galvanic cell in a chemical potential gradient (concentration cell) is usually employed to determine the transference number of ionic species in ionic compounds. When an oxide is placed under a chemical potential difference of a thermodynamic component, an electromotive force $E$ (emf, open cell voltage or open circuit voltage), induced by the difference in electrochemical potential of electrons at both solid/gas interfaces, develops across the oxide due to the redox equilibrium at the interfaces. Expanding Wagner's treatment ${ }^{16}$ into the ternary system of present concern, YSZ: $\mathrm{N}$ [or $\left(\mathrm{Zr}_{1-x} \mathrm{Y}_{x}\right) \mathrm{O}_{2-x / 2-3 y / 2} \mathrm{~N}_{y}$ ], one can find that the open cell voltage of the cell $\left(\mu_{\mathrm{O}_{2}}^{\prime}, \mu_{\mathrm{N}_{2}}^{\prime}\right), \mathrm{Pt}|\mathrm{YSZ}: \mathrm{N}| \mathrm{Pt},\left(\mu_{\mathrm{N}_{2}}^{\prime \prime}, \mu_{\mathrm{O}_{2}}^{\prime \prime}\right)$, under chemical potential differences of oxygen and nitrogen is given as

$$
E=\frac{1}{F}\left(\int_{\mu_{\mathrm{O}_{2}}^{\prime}}^{\mu_{\mathrm{O}_{2}}^{\prime \prime}} \frac{t_{\mathrm{O}^{2-}}}{4} \mathrm{~d} \mu_{\mathrm{O}_{2}}+\int_{\mu_{\mathrm{N}_{2}}^{\prime}}^{\mu_{\mathrm{N}_{2}}^{\prime \prime}} \frac{t_{\mathrm{N}^{3-}}}{6} \mathrm{~d} \mu_{\mathrm{N}_{2}}\right),
$$

where $\mu_{\mathrm{j}}$ and $t_{\mathrm{k}}$ denote the chemical potential of the thermodynamic components $\mathrm{j}\left(\mathrm{j}=\mathrm{O}_{2}, \mathrm{~N}_{2}\right)$ and the transference number of the ionic carriers $\mathrm{k}\left(\mathrm{k}=\mathrm{O}^{2-}, \mathrm{N}^{3-}\right)$, and $F$ is the Faraday constant. One can recognize in eqn (2) that the open cell voltage, $E$, is a measure of the transference number of the 
mobile ionic species, and that the partial contributions of the chemical potential differences of oxygen and nitrogen to $E$ are independent of each other. In particular, when the chemical potentials of nitrogen at both sides are equal, i.e., $\mu_{\mathrm{N}_{2}}^{\prime}=\mu_{\mathrm{N}_{2}}^{\prime \prime}$, one can determine the transference number of oxygen $t_{\mathrm{O}^{2}-}$ by measuring $E$ as a function of oxygen activity at one side e.g., $a_{\mathrm{O}_{2}}^{\prime \prime}\left[=\exp \left(\mu_{\mathrm{O}_{2}}^{\prime \prime} / \mathrm{R} T\right)\right]$ while $a_{\mathrm{O}_{2}}^{\prime}$ at the other side is kept constant, or

$$
t_{\mathrm{O}^{2-}}=\left.\frac{4 F}{\mathrm{R} T} \frac{\partial E}{\partial \ln a_{\mathrm{O}_{2}}^{\prime \prime}}\right|_{a_{\mathrm{O}_{2}}^{\prime}=\text { fixed }}
$$

\section{Experimental}

Single crystals of YSZ:N were prepared by the nitridation of $\mathrm{YSZ}$ (with $9.5 \mathrm{~mol} \% \quad \mathrm{Y}_{2} \mathrm{O}_{3}$ ) single crystals grown by the skull-melting technique. The nitridation was carried out in a graphite heated resistance furnace (FCT-FSW 100/ 150-2200-LA/PS) by thermal treatment in a nitrogen atmosphere $\left(1.06 \times 10^{5} \mathrm{~Pa}\right)$ at $1500{ }^{\circ} \mathrm{C}$ for $8 \mathrm{~h}$. The nitrogen content, determined by a Leco FE 300/400 analyzer, was $1.9 \mathrm{wt} \%$. Details of the nitridation and characterization of the samples are presented elsewhere. ${ }^{17} \mathrm{~A}$ single crystal of nitrogen-free YSZ (CrysTec GmbH, Berlin) was also employed for the purpose of comparison with the $\mathrm{N}$-doped specimen, as well as for confirming the validity of the present experiment.

For the measurement of open circuit voltage under an oxygen activity gradient, a galvanic cell was constructed with the configuration

$$
\mathrm{Pt}, a_{\mathrm{O}_{2}}^{\prime}, a_{\mathrm{N}_{2}}^{\prime}\left|\left(\mathrm{Zr}_{1-x} \mathrm{Y}_{x}\right) \mathrm{O}_{2-x / 2-3 y / 2} \mathrm{~N}_{y}\right| a_{\mathrm{N}_{2}}^{\prime \prime}, a_{\mathrm{O}_{2}}^{\prime \prime}, \mathrm{Pt}
$$

as illustrated in Fig. 1. A disk specimen measuring $20 \mathrm{~mm}$ diameter $\times 2 \mathrm{~mm}$ thickness was cut out of a single crystal bowl, and its planar surfaces were polished down to $1 \mu \mathrm{m}$ grit diamond. A pair of gas electrodes was then formed on both surfaces by the screen printing of platinum paste (Ferro $\mathrm{GmbH}$, no. 6402 1001). A piece of platinum gauze of $c a .0 .25 \mathrm{~cm}^{2}$ (Chempur GmbH, No 900338), which had been previously welded to a platinum lead wire of $0.3 \mathrm{~mm}$ diameter (Chempur $\mathrm{GmbH}$, No 903695), was attached at an appropriate position

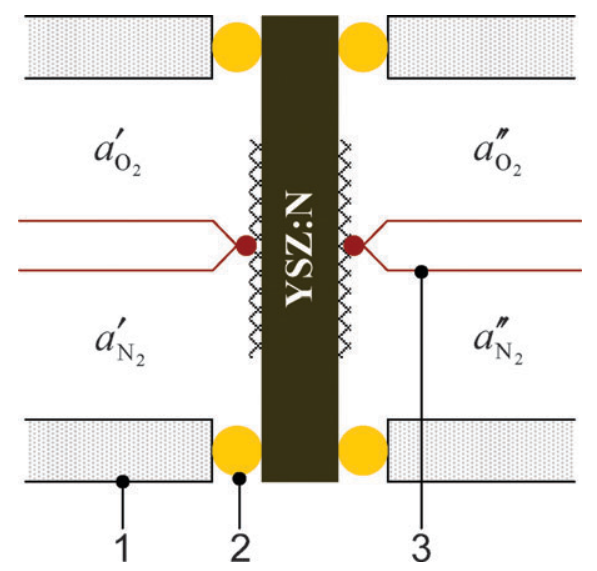

Fig. 1 Schematic of the galvanic cell employed: 1, $\mathrm{Al}_{2} \mathrm{O}_{3}$ tubing; 2, gold ring gasket; 3, K-type thermocouple. on each surface of the disk under a light spring pressure applied through the alumina sheath carrying platinum wire.

The gas-tightness of each compartment of the cell was achieved with the aid of a gold ring $(20 \mathrm{~mm}$ outer diameter $\times 1 \mathrm{~mm}$ thickness) mechanically pressed between the specimen and each alumina tube. A gas mixing system was used to separately control the activities of oxygen and nitrogen in each compartment. The specimen was first equilibrated at a fixed temperature in uniform activities of oxygen and nitrogen $\left(a_{\mathrm{O}_{2}}^{\prime}=a_{\mathrm{O}_{2}}^{\prime \prime}\right.$ and $a_{\mathrm{N}_{2}}^{\prime}=a_{\mathrm{N}_{2}}^{\prime \prime}$ ) by using an $\mathrm{N}_{2} / \mathrm{CO}_{2} / \mathrm{CO}$ gas mixture with a ratio of $10: 70: 20$. The open circuit voltage, $E$, was then measured against $a_{\mathrm{O}_{2}}^{\prime \prime}$ in the range $-20<\log a_{\mathrm{O}_{2}}^{\prime \prime}<-14$, achieved by a stepwise variation of the mixing ratio $10: x: y$ (such that $x+y=90$ and $50 \leq x \leq 87$ ) of the $\mathrm{N}_{2} / \mathrm{CO}_{2} / \mathrm{CO}$ mixture while keeping $a_{\mathrm{O}_{2}}^{\prime}$ fixed at the initial value. The nitrogen activities $a_{\mathrm{N}_{2}}^{\prime}$ and $a_{\mathrm{N}_{2}}^{\prime \prime}$ were also fixed throughout the experiment by fixing the mixing ratio of nitrogen gas to 0.1 . The oxygen activities of the gas mixtures in both compartments of the cell were monitored with additional independent calcia-stabilized zirconia oxygen sensors (ex situ), one side of which was exposed to air. The gas tightness of the cell was confirmed, as shown in Fig. 2(a), by a stable oxygen activity $a_{\mathrm{O}_{2}}^{\prime}$ on the left-hand side of the cell for a prolonged time upon an abrupt exchange of gas composition on the right-hand side. The open cell voltage measurement was carried out at different temperatures in the range of $750 \leq T /{ }^{\circ} \mathrm{C} \leq 850$ while keeping the sample and the oxygen sensors at the same temperature. The temperature of the specimen, which was monitored with two K-type thermocouples placed on both surfaces, was controlled to within $\pm 1{ }^{\circ} \mathrm{C}$.

\section{Results and discussion}

Fig. 2 shows the time variation of emf $E$ of galvanic cells with (a) undoped YSZ and (b,c) YSZ:N, respectively, along with $E$ of independent oxygen sensors upon stepwise changes of oxygen activity $a_{\mathrm{O}_{2}}^{\prime \prime}$ on the right-hand side of the cell $\left(a_{\mathrm{O}_{2}}^{\prime}, a_{\mathrm{N}_{2}}^{\prime}\right), \mathrm{Pt} \mid$ specimen $\mid \mathrm{Pt},\left(a_{\mathrm{N}_{2}}^{\prime \prime}, a_{\mathrm{O}_{2}}^{\prime \prime}\right)$ with $a_{\mathrm{O}_{2}}^{\prime}$ and $a_{\mathrm{N}_{2}}^{\prime}\left(=a_{\mathrm{N}_{2}}^{\prime \prime}\right)$ fixed. It is noted that each $y$-axis for the emf of the oxygen sensor in Fig. 2 and Fig. 3 has the same signal window (i.e. $200 \mathrm{mV}$ in Fig. 2 and $250 \mathrm{mV}$ in Fig. 3) as that for the emf of the specimen. In Fig. 2(a), one may first recognize that the change in emf, $\Delta E_{\mathrm{YSZ}}$, of the nitrogen-free YSZ is almost equal to that of the oxygen sensor for every step change of $a_{\mathrm{O}_{2}}^{\prime \prime}$. The observed behavior of $\Delta E_{\mathrm{YSZ}} / \Delta E_{\mathrm{Sensor}, \mathrm{R}} \approx 1$ is as expected, since both the YSZ specimen and oxygen sensor have an oxygen transference number of 1 , thus supporting the validity of the present measurement. On the other hand, the emf $E_{Y S Z: N}$ of the cell with N-doped YSZ behaves in a different way, as shown in Fig. 2(b); $\Delta E_{\mathrm{YSZ}: \mathrm{N}} / \Delta E_{\text {Sensor,R }}$ gets smaller with decreasing $E_{\mathrm{Sensor}, \mathrm{R}}$ or $a_{\mathrm{O}_{2}}^{\prime \prime}$ from the highest value corresponding to the gas mixture $\mathrm{N}_{2} / \mathrm{CO}_{2} / \mathrm{CO}=10 / 87 / 3$, which is more clearly seen in Fig. 2(c) for the result at a different temperature of $850{ }^{\circ} \mathrm{C}$.

The steady state values of $E_{\mathrm{YSZ}: \mathrm{N}}$ and $E_{\text {Sensor,R }}$ are plotted as a function of $\log a_{\mathrm{O}_{2}}^{\prime \prime}$ in Fig. 3. Compared to the ideal slope $2.303 \mathrm{R} T / 4 \mathrm{~F}$ of $E_{\mathrm{Sensor}, \mathrm{R}} v s . \log a_{\mathrm{O}_{2}}^{\prime \prime}$, the variation of $E_{\mathrm{YSZ}: \mathrm{N}}$ against oxygen activity gets less steep with decreasing oxygen activity, which unambiguously demonstrates that the 

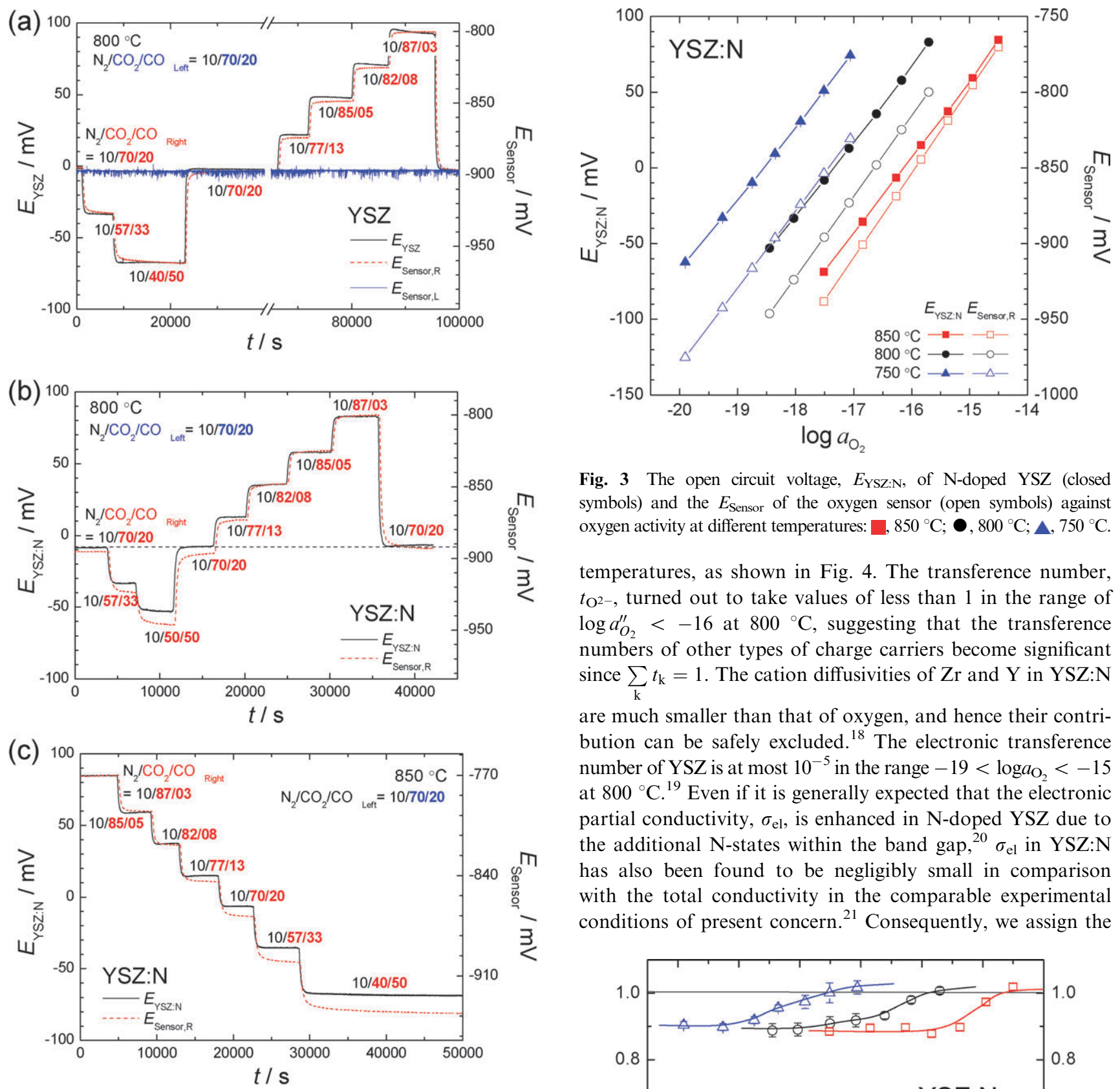

Fig. 2 Open circuit voltage $E$ vs. $t$ measured with galvanic cell $a_{\mathrm{O}_{2}}^{\prime}, a_{\mathrm{N}_{2}}^{\prime} \mid \mathrm{YSZ}: \mathrm{N}$ (or YSZ) $\mid a_{\mathrm{O}_{2}}^{\prime \prime}, a_{\mathrm{N}_{2}}^{\prime \prime}$ along with $E_{\mathrm{Sensor}}$ of zirconiabased oxygen sensors: (a) $E_{\mathrm{YSZ}}$ of undoped YSZ for a dummy test at $800{ }^{\circ} \mathrm{C}$, and $E_{\mathrm{YSZ}: \mathrm{N}}$ of N-doped YSZ at (b) $800^{\circ} \mathrm{C}$ and (c) at $850{ }^{\circ} \mathrm{C}$. The $a_{\mathrm{O}_{2}}^{\prime}$ value on the reference side was kept invariant at each temperature using a $\mathrm{CO}_{2} / \mathrm{CO}$ gas mixture with a fixed mixing ratio of $70: 20 . a_{\mathrm{N}_{2}}$ on both sides was also kept constant throughout the measurement by flowing $10 \mathrm{sccm} \mathrm{N}_{2}$ to each compartment. For controlling the experimental variable $a_{\mathrm{O}_{2}}^{\prime \prime}$ at the test electrode (right-hand side) of the cell (I), $\mathrm{CO}_{2} / \mathrm{CO}$ mixtures with a mixing ratio of $87: 3$ to $50: 40$ were employed.

transference number of oxygen in YSZ:N decreases with decreasing $a_{\mathrm{O}_{2}}$ due to eqn (3).

The transference number of oxygen in N-doped YSZ, $t_{\mathrm{O}^{2-}}$, was thus evaluated from the instantaneous slopes of the $E_{\mathrm{YSZ}: \mathrm{N}}$ isotherms as a function of oxygen activity at different

Fig. 3 The open circuit voltage, $E_{\mathrm{YSZ}} \mathrm{N}$, of N-doped YSZ (closed symbols) and the $E_{\text {Sensor }}$ of the oxygen sensor (open symbols) against oxygen activity at different temperatures: $\square, 850{ }^{\circ} \mathrm{C} ; \boldsymbol{\bullet}, 800{ }^{\circ} \mathrm{C} ; \boldsymbol{\Delta}, 750^{\circ} \mathrm{C}$.

temperatures, as shown in Fig. 4. The transference number, $t_{\mathrm{O}^{2-}}$, turned out to take values of less than 1 in the range of $\log a_{\mathrm{O}_{2}}^{\prime \prime}<-16$ at $800{ }^{\circ} \mathrm{C}$, suggesting that the transference numbers of other types of charge carriers become significant since $\sum_{\mathrm{k}} t_{\mathrm{k}}=1$. The cation diffusivities of $\mathrm{Zr}$ and $\mathrm{Y}$ in YSZ:N are much smaller than that of oxygen, and hence their contribution can be safely excluded. ${ }^{18}$ The electronic transference number of YSZ is at most $10^{-5}$ in the range $-19<\log a_{\mathrm{O}_{2}}<-15$ at $800{ }^{\circ} \mathrm{C} .{ }^{19}$ Even if it is generally expected that the electronic partial conductivity, $\sigma_{\mathrm{el}}$, is enhanced in N-doped YSZ due to the additional $\mathrm{N}$-states within the band gap, ${ }^{20} \sigma_{\text {el }}$ in YSZ:N has also been found to be negligibly small in comparison with the total conductivity in the comparable experimental conditions of present concern. ${ }^{21}$ Consequently, we assign the

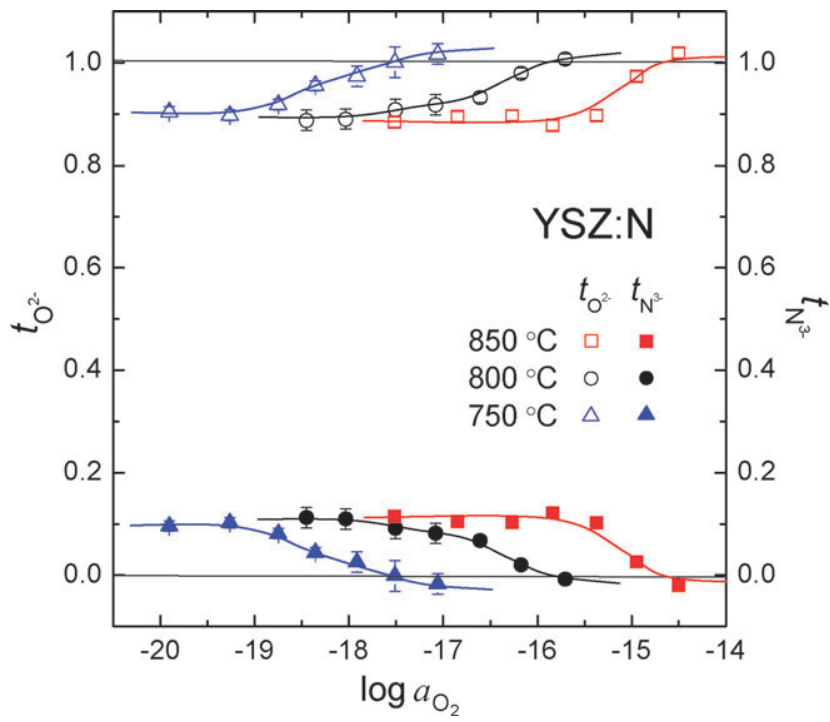

Fig. 4 The transference number of nitrogen $\left(t_{\mathrm{N}^{3}-}\right.$, closed symbol) and oxygen $\left(t_{\mathrm{O}^{2-}}\right.$, open symbol) in $\mathrm{N}$-doped $\mathrm{YSZ}$ at different temperatures: $\square, 850{ }^{\circ} \mathrm{C} ; \boldsymbol{\bullet}, 800{ }^{\circ} \mathrm{C} ; \boldsymbol{\Delta}, 750{ }^{\circ} \mathrm{C}$. The solid curves are for the visual guidance only. 
difference $1-t_{\mathrm{O}^{2}-}$ to the transference number of nitrogen $t_{\mathrm{N}^{3-}}$. The results are also shown in Fig. 4. At very low oxygen activities, YSZ indeed becomes electronically conducting. ${ }^{22}$

At a given temperature, the nitrogen transference number of YSZ:N increases from $t_{\mathrm{N}^{3-}} \approx 0$ with decreasing $a_{\mathrm{O}_{2}}$ and appears to be limited to a value of $c a$. 0.1 for the further decrease in $a_{\mathrm{O}_{2}}$. As the oxygen activity decreases, the equilibrium of the heterogeneous nitrogen incorporation reaction shifts towards the right-hand side of eqn (1), thus resulting in the increase of $t_{\mathrm{N}^{3}-}$, as is observed in Fig. 4. Furthermore, it is also recognized that $t_{\mathrm{N}^{3}-}$ takes a higher value with increasing temperature at a fixed oxygen activity. The activation enthalpy of oxygen diffusion in YSZ is known to be $\Delta H_{\mathrm{D}, \mathrm{O}}=0.7$ to $1 \mathrm{eV}$, depending on the composition, while that of nitrogen diffusion in YSZ: $\mathrm{N}$ is more than two times higher: $\Delta H_{\mathrm{D}, \mathrm{N}}=2$ to $2.5 \mathrm{eV} .{ }^{6}$ As a consequence, the higher activation enthalpy of nitrogen diffusion leads to an increasing $t_{\mathrm{N}^{3}-}$ with increasing temperature. Also, the nitrogen incorporation reaction, eqn (1), is endothermic, which is quite plausible considering that the binding energy of $\mathrm{N}_{2}(\mathrm{~g})$ is higher than that of $\mathrm{O}_{2}(\mathrm{~g})$. Consequently, YSZ accommodates more nitrogen in its lattice at higher temperatures. According to nitridation studies, the maximum nitrogen content at $2000{ }^{\circ} \mathrm{C}$ is approximately $15 \%{ }^{3}$

The time evolution of the open circuit voltage of the galvanic cell in Fig. 2 represents the progress of the surface equilibration, not that of the bulk, upon an abrupt change of oxygen activity in the gas phase. Once the surface of the oxide is equilibrated, the emf does not change with time, regardless of the degree of re-distribution of the non-stoichiometry in the bulk. In terms of the kinetics of the emf change, there is little noticeable difference between the undoped YSZ and the $\mathrm{N}$-doped YSZ. Thus, one may deduce that the heterogeneous catalytic activity of the N-doped YSZ is no worse than that of YSZ. In addition, changes in nitrogen transference number upon a shift of oxygen activity, as shown in Fig. 4, suggests that the concomitant shift of the thermodynamic equilibrium of eqn (1) occurs, and hence nitrogen is electrochemically active at the surface of YSZ:N. We noted that the YSZ:N crystals - depending on the time and the number of experimentslost nitrogen, and thus changed their transference numbers and resulting emf. The oxygen activity must always be kept low in order to avoid the loss of nitrogen. However, we are reminded that $\Delta E_{\mathrm{YSZ}: \mathrm{N}} / \Delta E_{\mathrm{Sensor}, \mathrm{R}}$ gets smaller with decreasing oxygen activity (Fig. 2b-c), implying the gradual enrichment of nitrogen at the test electrode, and that the emf changes of YSZ:N are reversible, at least during all the isothermal measurements, as shown in Fig. 2b. Hence, we assign the measured transference number to the presumably equilibrated part of the specimen close to the electrode, despite ambiguity over the stability of nitrogen in YSZ. We must point out that future work needs to focus on the equilibrium concentration of nitrogen in YSZ at lower temperatures than those yet studied in order to obtain a deeper understanding of the electrode properties and the transference of nitrogen.

\section{Summary and conclusion}

We have found that the nitrogen transference number in YSZ:N varies from 0 to 0.1 at oxygen activities in the range of $-20<\log a_{\mathrm{O}_{2}}<-14$ at temperatures in the range of $1023<T / \mathrm{K}<1123$, and the emf change of galvanic cells with YSZ:N is as fast as that with YSZ. Whether the non-zero nitrogen mobility together with the electrochemical activity of nitrogen at the oxide/gas interface will find practical applications, e.g., in nitrogen sensors, nitrogen and/or ammonia fuel cells, etc., remains questionable, as YSZ:N is not long-term stable in an oxidizing atmosphere.

\section{Acknowledgements}

This study (DFG Ja648/ 8-3, Le781/ 10-4) was funded by the German Science Foundation (DFG) within the priority program 1136 Substitution Effects in Ionic Solids.

\section{References}

1 Y. B. Cheng and D. P. Thompson, J. Am. Ceram. Soc., 1993, 76, 683-688.

2 M. Lerch, J. Am. Ceram. Soc., 1996, 79, 2641-2644.

3 M. Lerch, J. Lerch and K. Lerch, J. Mater. Sci. Lett., 1996, 15, $2127-2129$.

4 M. Lerch, J. Lerch, R. Hock and J. Wrba, J. Solid State Chem., 1997, 128, 282-288.

5 J. Wendel, M. Lerch and W. Laqua, J. Solid State Chem., 1999, 142, 163-167.

6 M. Kilo, M. A. Taylor, C. Argirusis, G. Borchardt, M. Lerch, O. Kaitasov and B. Lesag, Phys. Chem. Chem. Phys., 2004, 6, $3645-3649$.

7 M. A. Taylor, M. Kilo, C. Argirusis, G. Borchardt, I. Valov, C. Korte, J. Janek, T. Roedel and M. Lerch, Defect Diffus. Forum, 2005, 237-240, 479-484.

8 I. Kaiser-Bischoff, H. Boysen, C. Scherf and T. Hansen, Phys. Chem. Chem. Phys., 2005, 7, 2061-2067.

9 J.-S. Lee, M. Lerch and J. Maier, J. Solid State Chem., 2006, 179, 270-277.

10 I. Valov, R. A. De Souza, C. Z. Wang, A. Boerger, C. Korte, M. Martin, K.-D. Becker and J. Janek, J. Mater. Sci., 2007, 42, 1931-1941.

11 M. Lerch, J. Janek, K. D. Becker, S. Berendts, H. Boysen, T. Bredow, R. Dronskowski, S. G. Ebbinghaus, M. Kilo, M. W. Lumey, M. Martin, C. Reimann, E. Schweda, I. Valoy and H. D. Wiemhöfer, Prog. Solid State Chem., 2009, 37, 81-131.

12 T.-J. Chung, J.-S. Lee, D.-Y. Kim and H. Song, J. Am. Ceram. Soc., 1999, 82, 3193-3199.

13 G. Deghenghi, T.-J. Chung and V. Sergo, J. Am. Ceram. Soc., 2003, 86, 169-173.

14 I. Valov, C. Korte, R. A. De Souza, M. Martin and J. Janek, Electrochem. Solid-State Lett., 2006, 9, F23-F26.

15 I. Valov and J. Janek, Solid State Ionics, 2006, 177, 1619-1624.

16 C. Wagner, Z. Phys. Chem., 1933, B21, 25-41.

17 T.-C. Roedel, D. Wang, D. S. Su, M. Lerch, A. Prokofiev, K. D. Luther and W. Assmus, Cryst. Res. Technol., 2006, 41, 950-954.

18 M. Kilo, M. A. Taylor, C. Argirusis, G. Borchardt, B. Lesage, S. Weber, S. Scherrer, M. Schroeder and M. Martin, J. Appl. Phys., 2003, 94, 7547-7552.

19 J.-H. Park and R. N. Blumenthal, J. Electrochem. Soc., 1989, 136, 2867-2876.

20 T. Bredow, Phys. Rev. B: Condens. Matter Mater. Phys., 2007, 75, 144102.

21 I. Valov, V. Rührup, R. Klein, T.-C. Rödel, A. Stork, S. Berendts, M. Dogan, H.-D. Wiemhöfer, M. Lerch and J. Janek, Solid State Ionics, 2009, 180, 1463-1470.

22 J. Janek and C. Korte, Solid State Ionics, 1999, 116, $181-195$ 